\title{
International Expansion, Diversification and Regulated Firm Nonmarket Strategy
}

\author{
Santiago Urbiztondo ${ }^{\mathrm{a}}$, Jean-Philippe Bonardi ${ }^{\mathrm{b}}$ and Bertrand V. Quélin ${ }^{\mathrm{c}, *}$ \\ ${ }^{a}$ Fundación de Investigaciones Económicas Latinoamericanas, Buenos Aires, Argentina \\ ${ }^{\mathrm{b}}$ Faculty of Business and Economics, University of Lausanne, Lausanne, Switzerland \\ ${ }^{\mathrm{c}}$ HEC Paris, Jouy-en-Josas, France
}

\begin{abstract}
Previous studies have shown that regulated firms diversify for reasons that are different than for unregulated firms. We explore some of these differences by providing a theoretical model that starts by considering the firm-regulator relationship as an incomplete information issue, in which a regulated incumbent has knowledge that the regulator does not have, but the firm cannot convey hard information about this knowledge. The incumbent faces both market and nonmarket competition from a new entrant. In that context, we show that when the firm faces tough nonmarket competition domestically, going abroad can create a mechanism that makes information transmission to the regulator more credible. International expansion can thus be a way to solve domestic nonmarket issues in addition to being a catalyst for growth. Copyright () 2012 John Wiley \& Sons, Ltd.
\end{abstract}

\section{INTRODUCTION}

The international diversification of regulated firms issue, that is, their expansion into foreign countries, is an understudied yet important topic in the economics and management literature (Calzolari, 2004; Garcia Canal and Guillen, 2008; Kashlak and Joshi, 1994). The purpose of this paper is to offer a new rationale, complementary to those highlighted in previous literature, accounting for the geographical diversification of these firms and how they pick their target countries.

To date, the literature on the diversification of regulated firms has put forward an argument that can be summarized in the following way $^{1}$ : when regulated firms are engaged in difficult, even hostile and hightransaction-cost relationships with their regulatory authority, and as they do not have the opportunity to solve this transaction-cost issue through vertical

*Correspondence to: HEC Paris, Jouy-en-Josas, France. E-mail: quelin@hec.fr integration, they tend to diversify out of their core business and into unregulated activities. Russo (1992) found support for this argument in the case of US electric utilities. Kashlak and Joshi (1994) made a similar argument but point out that, instead of engaging in unregulated activities, regulated firms might also invest in international diversification if the firm's home market displays slow growth. These authors also find some empirical support for their argument by looking at US telecommunications operators.

From a theoretical point of view, however, this literature presents several limitations. First, the nature of the potentially hostile firm-regulator relationship is never clearly modelled. In most empirical studies, the nature of the relationships (from collaborative to hostile) is measured using variables relative to the 'Regulatory Climate' collected by analysts (see, for instance, Geiger and Hoffman, 1998, or Russo, 1992). These measures are instructive, but they are of little help in building a theory as to why these relationships impact corporate diversification. In what 
follows, we will propose that the core part of these sometimes hostile relationships is the imperfect information faced by both the regulator and the higher political institutions (e.g. government and parliament) delegating the task when the former has to make regulatory decisions. As highlighted by much of the Industrial Organization literature, regulated firms have private information that would be relevant for the regulator and their political principals. At the same time, it is also obvious that the firm, the regulator and the delegating politicians often have misaligned interests (Laffont and Tirole, 1993). As a result, when the firms try to convey soft, that is, non-verifiable information to the policymakers, they face a credibility issue. ${ }^{2}$ This makes firm-regulator and regulator-politician relationships difficult, which might thus impact the firm's decision to diversify out of its core market.

Second, even if the firm's relationships with the regulators are hostile, there are alternative strategies that firms can develop, such as lobbying or, more generally, nonmarket strategies (de Figueiredo and Tiller, 2001; Holburn and Van den Bergh, 2008). Following Baron (2001), we refer to nonmarket strategies as all the activities developed by firms to influence policy-makers. Many activities belong to nonmarket strategies, such as informational lobbying, interest group formation, campaign contributions, constituency building and media campaigns (Hillman et al., 2004). Baron (1995) shows many examples of how these nonmarket strategies can be effectively integrated with market strategies (such as price strategies, differentiation, technology development and diversification), in the context of both domestic and international strategies (Baron, 1997). Hence, there are good reasons to believe that regulated firms-at least the incumbents-will be efficient at developing these nonmarket strategies as (i) they are large entities and often have deep pockets (de Figueiredo and Edwards, 2007); (ii) they can build on organized constituencies, especially employees; and (iii) they generally have superior lobbying skills and capabilities developed through decades of interactions with policy-makers (Bonardi, 2004). In a study of US electric utilities, Bonardi et al. (2006) confirmed that these regulated firms develop nonmarket strategies and are often successful when they do so. Our aim is thus to answer the following questions: what role do these nonmarket strategies play in the firm-regulator relationship, and how do they impact diversification strategies? When are these nonmarket activities effective, and when are they not?

Third, although the existing literature on regulated firm nonmarket strategies might explain diversification, it cannot disentangle product and geographic diversifications. Both can indeed be strategic options for firms wishing to free themselves from very demanding or hostile regulatory supervision. But does this mean they are perfect substitutes for regulated firms, or is there something else that is achieved only through geographic diversification? The point that has not been taken into account so far in the existing literature is that diversification in unregulated or regulated sectors and in domestic or international markets has very different implications regarding firm-regulator relationships. Whereas investing in product diversification does little to change these relationships, international expansion helps the regulator to obtain (or forces him or her to take into account) comparable information about what the firms are doing in other (also regulated) markets. Whereas product diversification allows a partial escape from regulatory intervention (or its incidence over global profits), international diversification separates, but does not reduce, overall regulatory exposure. This will be a key aspect of our approach in this paper.

Beyond these theoretical issues, others appear when one looks at simple empirics regarding the international strategies of regulated firms. Consider for instance the analysis proposed by Kashlak and Joshi (1994) in their analysis of the geographical diversification of US telecom operators. These authors position the operators on the basis of two dimensions - the firm's core business growth and a measure of the regulatory restrictions the firm is facing in its home market. From there, they hypothesize that regulated firms will tend to diversify when core market growth is low and regulatory restrictions are high. We reproduce a comparable analysis of European telecommunication operators to check whether they follow a similar pattern regarding their decision to expand in foreign countries. Figure 1 plots the international strategies of former telecom monopolies in Europe. The $X$-axis displays the number of main lines per inhabitant as a proxy for the country's remaining market potential (a high value indicating low market growth potential), and the $Y$-axis displays the incumbent's market shares in the wireless home market as a proxy for how restrictive regulatory decisions have been for the former monopolies. ${ }^{3}$

Following Kashlak and Joshi's logic, operators in the top left quadrant of Figure 1 should also be the least international ones (as measured by the number of foreign countries they have invested in which Goerzen and Beamish (2003) call geographic scope), as they face lower regulatory restrictions in their home market and have sufficient market growth potential to exploit there. For the opposite reasons, 


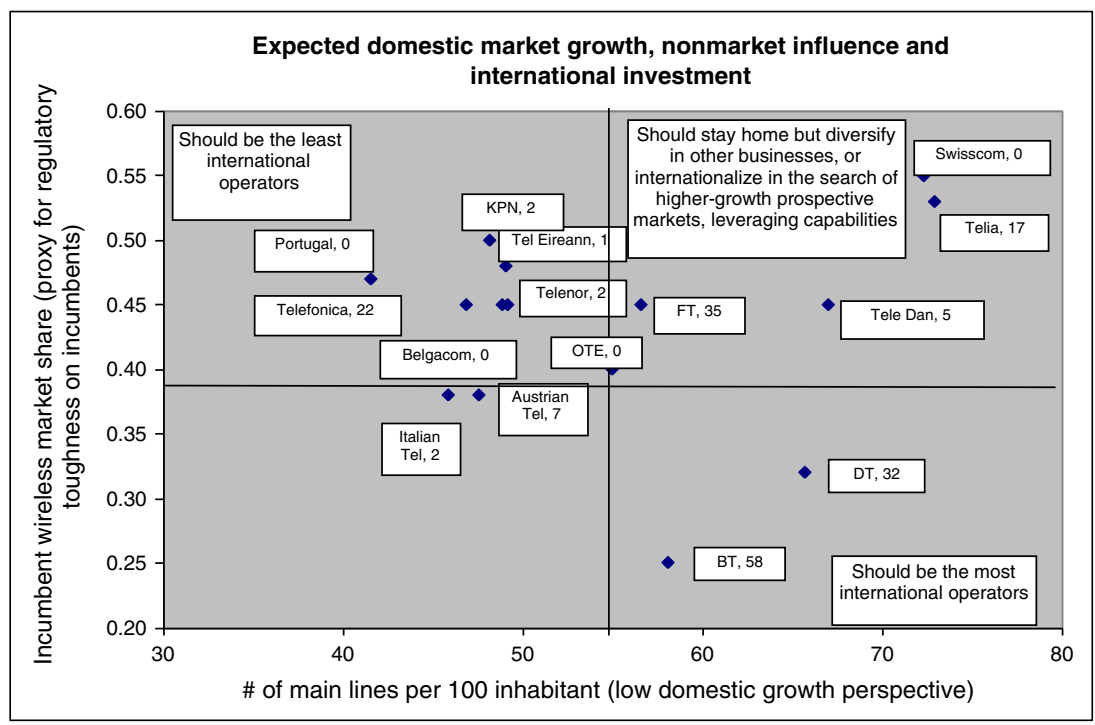

Note: The number of foreign countries entered by each operator is indicated after the operator's name.

Figure 1. Expected domestic market growth and international investment.

operators in the bottom right should be among the most international ones.

But, is this so? Figure 1 also indicates the internationalization strategy followed by various former monopolies, as measured by the number of foreign countries entered by each one of them since $1995 .^{4}$ We can see that various cases adjust to this prediction (such is the case of Portugal, KPN, Belgacom, British Telecom (BT) and Deutsche Telekom). However, contrary to what was predicted, there are also operators in the top left quadrant that are quite international (especially Spain's Telefonica). Similarly, there are some operators that are both strong at home and operate domestically in mature markets (top right quadrant in Figure 1), leaving no clear prediction regarding internationalization, according to the existing literature. France Telecom (FT) and Telia, for instance, internationalize much more than their strong nonmarket influence would predict for defensive reasons at home, suggesting their goal of achieving higher growth potential abroad.

How can this be explained? In the following, we suggest that there might be another potential set of factors influencing the international expansion of regulated firms, that is, the exploitation of information and visibility collected abroad used as a way to provide a benchmark for the regulator, thereby improving the nonmarket position of firms at home. If firms face a credibility deficit when they deal with domestic regulators-as they can only communicate soft and hard-to-verify information (Lyon and Maxwell, 2004) — and cannot easily compensate for this through alternative nonmarket tactics (such as campaign contributions, as in de Figueiredo and Edwards, 2007), ${ }^{5}$ they might increase the impact of their informational lobbying by providing comparative benchmarks that come from their foreign investments. This might be a key driver of these (but not all) operators' international expansion. On the other hand, regulated firms that are not challenged domestically might invest abroad for completely different reasons. For these firms, such as FT in our sample, investing in institutionally close countries might not be a critical factor.

We also show that this has implications for the destinations where regulated firms invest. For the firm to use international expansion as a way to build a credible benchmark, there needs to be some institutional proximity between the home and target countries. We call institutional proximity the degree to which two countries share similar institutional arrangements and formal institutions in their regulatory system. ${ }^{6}$ Firms that try to build a relevant benchmark for their domestic regulator will have to invest in close countries more often. On the other hand, firms that do not need to build this benchmark (because they already have a strong nonmarket influence over their home regulator) will relatively tend to invest in institutionally far (different) countries, especially if these countries display higher potential growth. 
Going back to the case of European telecom operators, we explore this proposition and calculate an 'index of alike internationalization' - that is, an index of investment in institutionally close countries-as the ratio of the number of neighbour countries (in this case Western European countries) divided by the total number of countries in which the operator has invested. ${ }^{7}$ In Figure 2, we plot this index (on the $Y$-axis) with the operator's remaining market shares in the wireless segment (again, as a proxy of the firm's faced regulatory toughness, which is also a measure of its nonmarket influence at home). The outcome is quite sharp: all the operators are positioned either in the top left or in the bottom right segments of the graph. Operators that have relatively low nonmarket influence/capabilities and that have decided to concentrate their international investment on neighbouring countries are in the top left quadrant. Operators in the bottom right segment, who face softer pro-entrant regulations and thus are said to have strong nonmarket influence in their home market, tend to invest in countries that are (relatively) farther from them institutionally. This indicates that companies facing a nonmarket disadvantage domestically tend to invest nearby, whereas companies that hold a nonmarket advantage domestically tend to invest farther from home. ${ }^{8}$

One final comment is in order regarding the relation of our paper with Calzolari (2004). He also considers the regulation of a monopolist multinational firm by two independent national regulators in the context of lobbying under asymmetric information, but a multinational enterprise's (MNE) private information regards a single production parameter determining interdependent costs in both countries. Depending on cross-effect of production on costs across countries, the MNE can exploit different social preferences of national regulators depending on the nationality of the owners of the firm, enjoying also an improved bargaining position by threatening to shutdown production in a more demanding regulatory environment. In that regard, regulated firms also find a strategic benefit from internationalization within the same regulated industry. Yet, although less technical, our model tries to capture a situation where the MNE competes with other firms in each country and the internationalization benefit emerges from a superior capacity to transmit favourable information into the national regulatory proceedings instead of coming from cost externalities emerging from the level of production in each country or from a more credible exit threat by the MNE, which we find less appealing for infrastructure industries with large sunk costs.

The purpose of the model developed in the next section is to formally demonstrate the intuitions illustrated in the case of the European telecom operators. The rest of the paper is organized as follows. Section 2 presents the foundation of a model that could account for some of these anomalies. The formal model itself is analysed in Section 3. Section 4 discusses the results and makes some conclusions.

\section{MODEL ASSUMPTIONS}

In our model, we consider one sector that has been traditionally regulated and builds on an infrastructure

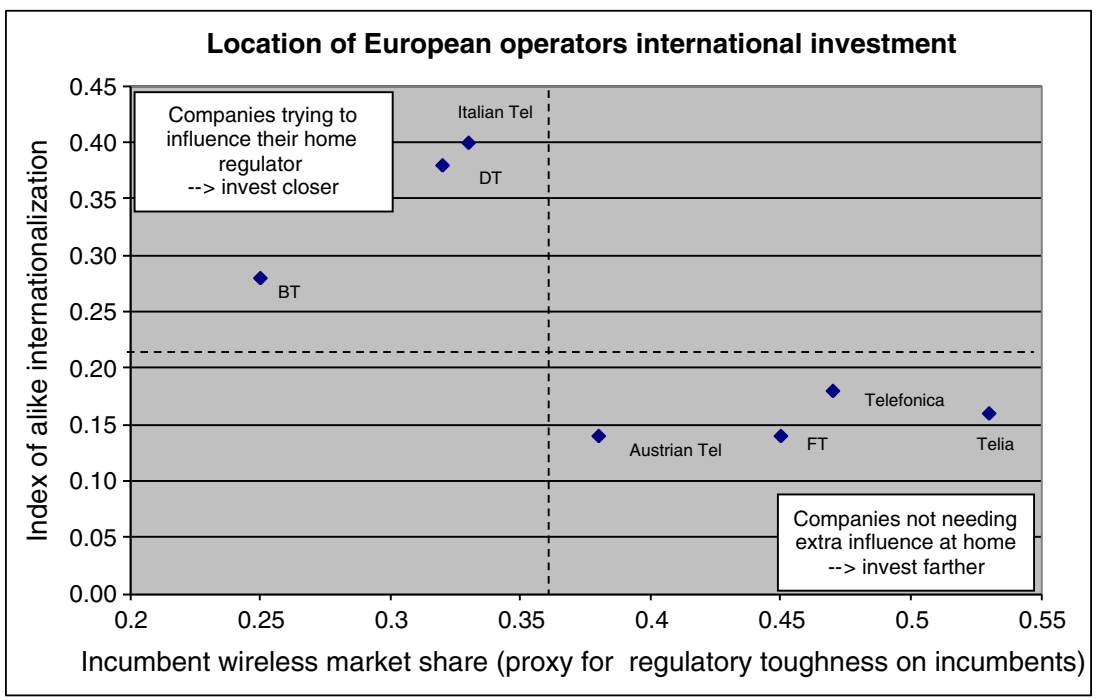

Figure 2. Location of European operators' international investment. 
network (i.e. telecommunications or electricity) in one country. The policy issue has to do with the determination of an access price (for fixed, wire-line services) that an entrant firm has to pay to the incumbent and owner of the infrastructure. The game includes one regulator $(R)$ and two firms/interests, denoted by $j=I$, $E$ : one firm is the incumbent $(I)$ and the other is the entrant $(E) .{ }^{9}$ We first consider a case where each firm is purely domestic, and then we analyse the changes when one firm expands into a foreign country. ${ }^{10}$ Final users (and governments in general) benefit when the policies implemented adjust well to the true underlying conditions (state of nature), which is more likely when the regulator enjoys less discretion and is required to base him or her decisions on publicly available elements.

In order to capture the basic intuition, various simplifying assumptions are adopted. First, we make some assumptions, which, although considered reasonable, do minimize the theoretical options regarding possible signalling games oriented to transmit private information. Second, we assume that a first-best regulation (i.e. marginal cost pricing) is feasible under complete information. $^{11}$

\subsection{The Firms and the Regulator}

As in Bernheim and Whinston (1986) or Grossman and Helpman (1994), the two interests behave as principals that seek to contract with the regulatory authority for the policy, and the regulatory authority is thus a (de facto) common agent of the two interests. ${ }^{12}$ The regulator, in turn, is the formal agent of higher political government institutions (who we assume truly represents the final users of the regulated service).

Objective functions for the regulator and the firms are built upon quadratic loss functions regarding the most preferred policies by each agent (Baron, 2001); firms lobby for their most desired policy through transfers/support transmitted to the regulator; the regulator balances efficiency (consumer representation or industry performance, based on available information) and its private interest (support received from interest groups-regulated firms-minus expected penalties to be incurred in case he or she is proven to be adopting biased or inefficient decisions).

A key assumption in our model, then, is that regulators tend to adopt policies that 'cover their back'. By this, we mean that an important aspect for regulators is to avoid being penalized by the governing politicians supervising them. Hence, when a piece of information that might have some credibility is signalled to politicians, it will be costly for regulators to ignore it (Bonardi et al., 2006). Thus, as long as regulators can relatively credibly justify their policy choices using this piece of information, their 'back is covered'. This assumption fits with regulatory practices as explicated by Hyman (2000).

It is noteworthy that the modelling implication of this assumption is that regulators generally do not set up truth-revealing incentive mechanisms to obtain the best information. Even less so is the case for government officials dealing with multiple issues and delegating regulation to specialized bodies. Even if this mechanism would seem to be more elegant and in line with now-standard information economics models (Laffont and Tirole, 1993), we concentrate on keeping our model closer to real regulatory practice.

To maximize efficiency - for a given set of transfers or supports received from regulated firms-the regulator must base him or her decision on the information he or she has regarding the cost of providing access to the existing network operated by the incumbent firm. An access price (or rate) set too high would allow the incumbent to retain excessive monopoly rents, whereas an access price set too low would eventually lead to a deterioration of the network coverage and/or quality, ultimately hurting the final users (i.e. overall performance) of the regulated services in both cases. Thus, as the regulator is imperfectly informed about the true cost of access, his or her decision could be biased away from efficiency. To minimize this bias, higher political government officials (and final users) would welcome credible information that pushes the regulator to minimize the potential error of his or her cost estimate.

\subsection{Network Costs, Information and Reports}

The marginal cost of the existing network is given by $C(\delta)$, where $\delta$ is a vector of both idiosyncratic and common parameters (such as country size, income, density, cost of capital and available technology adjusting to those conditions); $C(\delta)$ can be positively correlated across different countries, depending on their structural similarities with respect to their key parameters $\delta$.

The informational assumption is that (all) firms know $\delta$ in the countries where they participate, but the regulator and the higher political government officials $(G)$ do not. More precisely, the regulator receives an unbiased signal from nature-which is, in fact, his or her honest deconstruction of all the evidence consulted to determine those parameters-but higher political government officials are fully uninformed. ${ }^{13}$ 
Firms supply reports with information about the state of the world regarding $\delta$, which contains both 'hard' (verifiable) and 'soft' (unverifiable) information. Verifiable information truncates the support of the cost function within which $R$ receives the unbiased signal from nature: the hard (but selective) information supplied by the firms convinces $R$ that $\delta^{\max } \geq \delta \geq$ $\delta^{\text {min }}$; unverifiable information is used by $R$ to construct its prior belief about the cost C. Thus, both $R$ and $G$ understand that firms could safely report $C\left(\delta^{\mathrm{r}}\right)$, where $\delta_{j}^{\mathrm{r}} \in\left[\delta^{\min }, \delta^{\max }\right] .{ }^{14}$

The regulator has only one instrument at hand: setting an access price $(a)$, which in turn determines both the benefits obtained by the incumbent and the entrant, and the overall performance of the sector. ${ }^{15}$

When one of the firms is a multinational $(M)$, the report it sends can have different advantages regarding its credibility. First, this signal could become more compelling or credible for both $R$ and $G$ because some of the determinants of the network costs are common across countries (i.e. $M$ is in a better position to convey information about the other country's situation in a more coherent and credible way), and/or because $M$ 's various reports have to be relatively consistent across countries and thus should be less biased (i.e. $M$ would have to provide some relatively damaging hard information-for instance, if $M$ is the incumbent, it might provide information, allowing a reduction in $\left.\delta^{\max }\right)$. Second, even if $R$ is not further convinced by this new piece of information (because he or she had already consulted it on his or her own or because there is no implication for increased consistency), $G$ would now know that such information was indeed exposed to $R$ during the regulatory proceedings and could adopt the report as its own prior or benchmark to examine $R$ 's choices in implying deviations from it. Third, $G$ might be less aware than $R$ about the idiosyncratic differences of costs across (otherwise similar) countries and thus might adopt this (visible) report as its own prior on which to base its posterior monitoring activity.

In this paper, and only for modelling reasons, we adopt the following assumption: a report by $M$ does not modify $C$ 's support (i.e. $\left[C\left(\delta^{\min }\right), C\left(\delta^{\max }\right)\right]$ remains unchanged), but it becomes the expected policy by $G$, forcing $R$ to justify more carefully - with a cost-the policies deviating from it. Thus, higher level political government officials monitor $R$ 's use of the information supplied by $M$, inducing $R$ to give more weight to $M$ 's reports because the correlation of network costs across countries is expected to be higher.

\subsection{Games Sequence}

The sequence of the game goes as follows:

- First, nature chooses the vector $\delta$ of idiosyncratic and common technology parameters.

- Second, government officials state their monitoring strategy regarding the policy chosen by the regulator, including the penalties they will apply if he or she is found to be following his or her own agenda (making biased decisions by neglecting some verifiable information submitted by the regulated firms).

- Third, firms observe the true $\delta$ in the countries where they participate and send signals (reports $\left.C\left(\delta_{j}^{\mathrm{r}}\right)\right)$, which inform $R$ that $C$ 's support is $\left[C\left(\delta^{\mathrm{min}}\right)\right.$, $\left.C\left(\delta^{\max }\right)\right]$.

- Fourth, firms exert pressure on the regulator to influence the price of access he or she will set.

- Fifth, the regulator implements policy (sets the access price $a^{*}$ ) on the basis of the incentives faced (i.e. the information collected, the pressure of firms in the political regulatory process and the expected penalty for disregarding verifiable information supplied by regulated firms).

- Finally, pay-offs develop.

The Nash equilibrium of this incomplete information game is solved backwards: given the informational lobbying directed to convince the regulator about favourable costs of access, in anticipation of the regulator's reaction function, both firms simultaneously choose their supports, and then, given these decisions, a policy is implemented by the regulatory authority.

\section{MODEL ANALYSIS}

As pointed out, the key issue for the regulator is the determination of the access price, $a$, within an interval depending on possible values of $C(\delta)$ as shown in Figure 3: $a \in\left[C^{\min }, C^{\max }\right] . a^{*}=C$ would be the firstbest policy. The unbiased signal (within $C$ 's support, resulting from the reports and information collected) received by $R$ determines his or her prior belief about $C$, called $C^{P}$.

The utility function for firm $j=I, E$ is

$u_{j}(a)=-\alpha_{j} \times\left(a-C^{j}\right)^{2}$,

where $C^{j}$ denotes firm $j$ 's preferred report (incumbents prefer $C^{\max }$, i.e. $C^{I}=C^{\max }$; and entrants prefer $C^{\min }$, i.e. $\left.C^{E}=C^{\mathrm{min}}\right), \alpha_{j}$ denotes the importance of the policy 


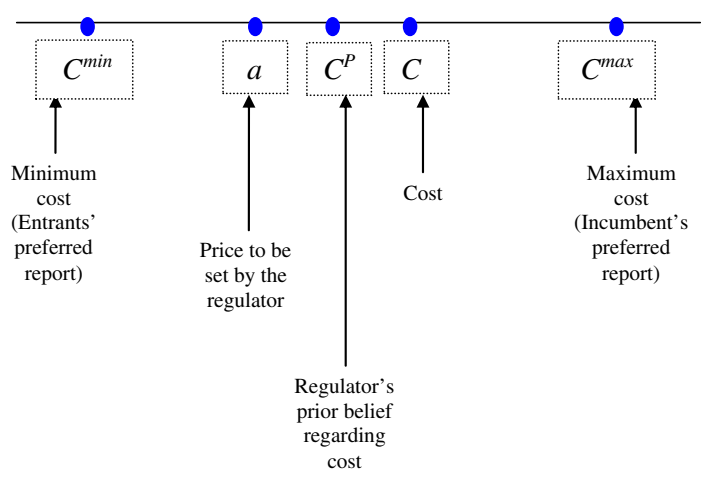

Figure 3. Policy space.

for firm $j$, and it turns out to also represent the nonmarket strength or influence of this firm in the regulatory game. ${ }^{16}$ Naturally, these utilities are negative unless we add a positive constant, but it is important that the maximum level be reached at $a^{*}=C^{j}$ and that the marginal disutility increases with further departures from this point.

Firms offer support $s_{j}(a)$, and policy preferences for each firm are the following: $U_{j}=u_{j}(a)-s_{j}(a)$. For simplicity, the support functions are assumed to be linear, in the following way: $s_{I}(a)=\omega \times\left(a-C^{E}\right)$ and $s_{E}(a)=\lambda \times\left(C^{I}-a\right)$. That is, the incumbent transfers to the regulator $\omega$ per unit of deviation from its lessdesired policy $\left(C^{E}\right)$ and the entrant pays his or her $\lambda$ per unit of deviation from his or her own less-desired policy $\left(C^{I}\right)$. Thus, $s_{I}(a) \geq 0$ and $s_{E}(a) \geq 0$.

Although in a 'truthful equilibrium' (Bernheim and Whinston, 1986) the marginal supports offered by each principal reflect their marginal utilities for each feasible policy chosen by the agent (and these decrease as they approach each principal's preferred point), we restrict our attention to linear incentive schemes for three main reasons. First, because at the equilibrium (correctly anticipated by each principal), the linear incentive schemes do coincide with each principal's marginal utility. Second, because we find it unrealistic that the regulated firms formally expose a support function announcing each marginal reward attached to all possible actions taken by the regulator, the agent would, at most, perceive the rewards as linear schemes (and react accordingly to them). Third, working with linear incentive functions simplifies the mathematical solution of the model.

More generally, even though our restriction implies that the support functions are not truthful everywhere, they are truthful at the equilibrium (i.e. they reflect the marginal utility derived from the equilibrium policy chosen by the agent), and they are 'relatively truthful' off the equilibrium, leading to a unique Nash equilibrium. In other words, this would be an example of what Bernheim and Whinston (1986) described as 'an irrelevant way' in which equilibrium (linear) strategies depart from (fully) truthful ones.

The outcome for consumers-allocative efficiency $P$ - symmetrically depends on the difference between the access price and the true marginal cost of access, that is, $P(a)=-\theta \times(a-C)^{2}$. (Ex ante, though, expected performance is maximized when $a^{*}=C^{P}$.) That is, setting an access price above the marginal cost of access to the network triggers a higher final price $P^{\mathrm{f}}$ that hurts consumers, whereas an access price below that cost leads to a deterioration of investment to maintain and expand the network, also hurting the final users.

\subsection{Regulator and Firm Nonmarket Strategies}

In our model, we concentrate on two types of nonmarket strategies: (i) support (of any kind) provided by firms to the regulator (as in Baron, 2001) and (ii) informational lobbying to convey soft information. As both firms (the incumbent and the entrant) provide nonmarket support in favour of certain regulatory decisions, the regulator is assumed to balance the support received from the interest groups (regulated firms $I$ and $E$ ) with its intrinsic willingness for good performance (as representing consumer surplus or allocative efficiency out of first-best policy or marginal cost pricing), so that

$U_{R}=P(a)+s_{I}(a)+s_{E}(a)$.

As $R$ does not observe $\delta$ (within $\left[\delta^{\min }, \delta^{\max }\right]$ ), his or her decisions are based on his or her beliefs about it. At the same time, without any other constraint by their political superiors, $R$ can justify any policy that he or she chooses on the basis of $\delta \in\left[\delta^{\min }, \delta^{\max }\right]$ as the optimal performance attainable, given the information that he or she has about $\delta$. Indeed, even though the higher political officials are fully uninformed regarding the support of the cost function, the two firms are informed about the support within which $R$ has to make his or her decision, and they could claim a review if he or she steps outside that range. Without loss of generality, we assume that $R$ 's expected cost $\left(C^{P}\right)$ is equally distant from $C\left(\delta^{\mathrm{min}}\right)$ and $C\left(\delta^{\max }\right)$ (i.e. $\left(C^{P}\right)=$ $\left.\left[C\left(\delta^{\mathrm{min}}\right)+C\left(\delta^{\mathrm{max}}\right)\right] / 2\right)$, and that both firms know this.

Can a multinational firm become more credible and send a report to which the regulator gives more weight? On the basis of the discussion at the end of the previous section, the answer to this question would be: Yes, it can. In particular, the regulator could be penalized if found to have overlooked or minimized 
information from another comparable country that was submitted during the regulatory process, and as multinationals have much better access to such information than do other parties, firms obtain a strategic advantage through internationalization. The magnitude of this advantage depends on the expected penalties faced by the regulator, which in turn depend on the importance given to the foreign country as an information benchmark by the higher political officials themselves (this is known before the firms play out their strategies in front of the regulator-see the time sequence spelled out earlier). In general, then, if a regulator faces a multinational, his or her discretion is reduced, as he or she needs to implement a policy that gives more (or even full) weight to the information supplied by $M$.

As regard the utility function of the regulator once such penalties are feasible, the linear translation of the assumption spelled out in the previous section results in the following:

$$
\begin{aligned}
U_{R}= & -\theta \times\left(a-C^{P}\right)^{2}+S_{I}(a)+S_{E}(a) \\
& -F \times\left(a-C^{M}\right)^{2},
\end{aligned}
$$

where the last term is added reflecting the increased cost for $R$ if he or she deviates from the report $C^{M}$ (either because of the risk of being penalized by $G$ or because of the more careful justification for increasing departures of the policy implied by such a report).

Yet, for the sake of simplicity (and in posterior computations), the first and third terms of the preceding function could be (imperfectly) combined, to re-express $R$ 's utility function in the following way:

$$
U_{R}=-\hat{\theta} \times\left(a-C^{P M}\right)^{2}+S_{I}(a)+S_{E}(a),
$$

where $\hat{\theta}>\theta$ represents the higher disutility (including the expected penalty and/or the effort to justify a policy based on own information) that $R$ faces when the policy chosen deviates from the one that he or she is supposed to implement, which now, instead of being his or her prior $C^{P}$, becomes a prior that gives more weight to the report $C^{M}$ (or $\delta_{M}^{\mathrm{r}}$ ) sent in by the multinational firm. ${ }^{17}$ In other words, the use that $G$ makes of the report $C^{M}$ ends up reflecting changes in the decisions adopted by $R$, as if he or she cared more about the performance of the sector $(\hat{\theta}>\theta)$ and had a prior belief $C^{P M}$ that is closer to the preferred policy by the multinational firm (i.e. $C^{I}>C^{M}>C^{P M}>C^{P}$ ). Naturally, as the penalty $F$ tends to disappear (in the end, reaching the case in which there is no multinational), the parameters of $R$ 's utility function tend towards those defined in the absence of multinational firms. Notice that if both the incumbent and the entrant in a given country are multinational firms, then the regulator would have to combine the (conflicting) information provided by both of them, using each report as relative proof to empirically base his or her decision according to the different weights that he or she believes (or has announced) $G$ would give to the different sources (i.e. trying to adjust its policy to the optimal one that would be taken by the politicians themselves on the basis of the importance they give to the information supplied by the two firms, which depends on which foreign countries they use for their reports). In that regard, the discretion enjoyed by the regulator is further reduced, and thus the productivity of each transfer offered by the two firms is also lower, reducing the rents retained by the regulator.

\subsection{Complete Information}

Under complete information, a simple (first-best) solution is reached: $a^{*}=C(\delta)$. This is derived from the regulator's utility function when $s_{I}(a)=s_{E}(a)=0$, as has to be the case because, with complete information, the regulator would be caught responding to interest groups - and would presumably be heavily penalized by his or her political superiors or the courts-if $a^{*} \neq$ $\mathrm{C}(\delta)$. The outcome in this case displays marginal cost pricing and no space for the development of a credibility issue. In fact, no nonmarket strategies could take place once the regulator could not justify departing from first-best policies.

The general case of regulated sectors, however, is one of incomplete information. As explained before, this is what creates the sometimes hostile relationships between the regulated firms and the regulator. What then happens under incomplete information in our setting when firms are purely domestic actors? Later, we explore the nature and implications of incomplete information concerning the 'true state of the world'.

\subsection{Incomplete Information but No Multinational Firm}

Under our previous assumptions, and leaving aside the verifiable components of the reports that define the range of possible costs (i.e. $\left.\left[C\left(\delta^{\mathrm{min}}\right), C\left(\delta^{\mathrm{max}}\right)\right]\right)$, the soft reports sent in by each firm cannot be verified in a court of law, and thus it is completely up to the regulator to announce his or her conclusion regarding the true state of nature within this range. So, whatever decision is made by $R$ within this range, no penalty can be imposed on him or her. Thus, once the support of the cost function $\left[C\left(\delta^{\min }\right), C\left(\delta^{\max }\right)\right]$ is determined (and known 
by the regulator and the two firms), the common agency equilibrium $\left(s_{I}^{*}(a), s_{E}^{*}(a), a^{*}\right)$ is defined as

$$
a^{*} \in \arg _{a} \max P(a)+s_{I}^{*}(a)+s_{E}^{*}(a)
$$

with $s_{I}^{*}(a) \in \arg _{s_{I}(.)} \max -\alpha_{I}$

$$
\begin{aligned}
& \times\left[a^{*}\left(s_{I}(.), s_{E}^{*}(.)\right)-C^{I}\right]^{2} \\
& -s_{I}\left(a^{*}\left(s_{I}(.), s_{E}^{*}(.)\right)\right)
\end{aligned}
$$

$$
\text { and } \begin{aligned}
s_{E}^{*}(a) & \in \arg _{s_{E}(.)} \max -\alpha_{E} \\
& \times\left[a^{*}\left(s_{I}^{*}(.), s_{E}(.)\right)-C^{E}\right]^{2} \\
& -s_{E}\left(a^{*}\left(s_{I}^{*}(.), s_{E}(.)\right)\right) .
\end{aligned}
$$

We assume that the two principals (firms) decide on their support schedules first and then the agent (regulator) reacts to them. Nevertheless, when the firms make their choice, each of them incorporates the regulator's reaction function, as determined by the first-order condition of his or her optimization problem. As each principal attempts to make a separate prediction of the support schedule offered by the other principal, both principals recognizing that the agent will optimally react to their aggregated support schedules, equilibrium requires that those predictions are correct.

From the convexity of the utility functions of all players, an interior solution for the two support schedules falls short of a coordinated solution between the two principals, whereby they would agree on the overall incentive to be provided to the agent. Furthermore, assuming that the support schedules are differentiable, the interior solution is obtained in the following way. First, from $R^{\prime}$ 's problem, the first-order condition yields $a *=\frac{(\omega-\lambda)}{2 \theta}+C^{P}$. Then, if the two principals cannot offer support $(\omega=\lambda=0)$ or if their support simply balances out as they provide equal absolute incentives to the regulator $\left(\omega^{*}=\lambda^{*}\right)$, the equilibrium access price $a^{*}$ is set at the expected (prior) best-policy level $C^{P}=E(C)$. (The chosen policy, though, could turn out to be ex-post inefficient if the signal received by $R$ was biased.)

Next, taking into account $R$ 's reaction function to their own problems (i.e. replacing the previous expression for $a^{*}$ in their optimization problems), both competing firms decide on their support schedules (i.e. on the values of $\omega^{*}$ and $\lambda^{*}$ ), according to the following two first-order conditions:

$$
\begin{aligned}
\omega: & -\left(\alpha_{I} / \theta\right)\left[(\omega-\lambda) / 2 \theta+C^{P}-C^{I}\right] \\
& -\left[(\omega-\lambda) / 2 \theta+C^{P}-C^{E}\right]-\omega / 2 \theta=0, \\
\lambda:+ & \left(\alpha_{E} / \theta\right)\left[(\omega-\lambda) / 2 \theta+C^{P}-C^{E}\right] \\
& +\left[(\omega-\lambda) / 2 \theta+C^{P}-C^{I}\right]-\lambda / 2 \theta=0 .
\end{aligned}
$$

Solving this system of equations for an interior solution, we have ${ }^{18}$

$$
\begin{aligned}
\omega^{*}= & -2\left[\alpha_{I} \theta\left(C^{P}-C^{I}\right)+\theta^{2}\left(C^{P}+C^{I}-2 C^{E}\right)\right. \\
& +\alpha_{E} \alpha_{I}\left(C^{E}-C^{I}\right] /\left(\alpha_{E}+\alpha_{I}+3 \theta\right), \\
\lambda^{*}= & 2\left[\alpha_{E} \theta\left(C^{P}-C^{E}\right)+\theta^{2}\left(C^{P}+C^{E}-2 C^{I}\right)\right. \\
& +\alpha_{E} \alpha_{I}\left(C^{I}-C^{E}\right] /\left(\alpha_{E}+\alpha_{I}+3 \theta\right) .
\end{aligned}
$$

From these two equations, we obtain

$$
\begin{aligned}
\omega^{*}-\lambda^{*}= & 2 \theta\left[\alpha_{E}\left(C^{E}-C^{P}\right)+\alpha_{I}\left(C^{I}-C^{P}\right)\right. \\
& +\theta\left(C^{I}+C^{E}-2 C^{P}\right] /\left(\alpha_{E}+\alpha_{I}+3 \theta\right),
\end{aligned}
$$

and replacing this expression in the regulator's choice function $a *=\frac{(\omega-\lambda)}{2 \theta}+C^{P}$, we have

$$
\begin{aligned}
a *= & {\left[\alpha_{E}\left(C^{E}-C^{P}\right)+\alpha_{I}\left(C^{I}-C^{P}\right)\right.} \\
& +\theta\left(C^{I}+C^{E}-2 C^{P}\right] /\left(\alpha_{E}+\alpha_{I}+3 \theta\right)+C^{P} .
\end{aligned}
$$

From the first of the last two equations, it is easy to characterize the symmetric case: if the two firms have the same intensity of preferences or capacity to influence the regulatory policy (i.e. if $\alpha_{E}=\alpha_{I}$ ), and $R$ 's expected value $C^{P}$ is halfway between the two extreme policies supported by the interest groups (i.e. if $\left.C^{P}=\left(C^{I}+C^{E}\right) / 2\right)$, then $\lambda^{*}=\omega^{*}$, leading to $a^{*}=C^{P}$. So, under this scenario, if the true state of nature $C$ coincides with $C^{P}$, the policy implemented matches the first-best option that maximizes performance $P(a)$. In the symmetric case where the two interests have equally intensive preferences and are also equally distant from the expected state of nature $C^{P}$ regarding their preferred policies, the (marginal) supports offered by each regulated firm are the same, and the policy chosen by $R$ turns out to be the one that maximizes expected allocative performance $P(a)$.

We can also verify that when $C^{P}=\left(C^{I}+C^{E}\right) / 2$, then $\omega^{*}>\lambda^{*}$ if $\alpha_{I}>\alpha_{E}$, which means that the most interested principal offers the highest support. In that sense, adopted policies will generally be ex-ante biased with respect to $R$ 's belief (as long as the strength of principals 
through nonmarket strategies are unequal), but the biases cannot be proven ex post by any one of the participants. Thus, it is natural that higher political government officials $(G)$ would regret $R$ 's discretion and would prefer to find ways to audit his or her decisions or force him or her to reduce such discretion. They would welcome, of course, information that minimizes the risk of implementing an ex-post biased policy regarding the true state of nature $C$.

More generally, from the last equation, and recalling that $C^{I}>C^{P}>C^{E}$, we can check that $a^{*}$ increases with $C^{P}$, it decreases with $\alpha_{E}$ and it increases with $\alpha_{I}$. Also, $a^{*}$ moves closer to $C^{P}$ when $\theta$ increases, that is, when the performance is more affected by the policy chosen. ${ }^{19}$ The numerical example developed in Table 1 illustrates these various results.

Reading the results progressively from columns 1 to 6 of Table 1, we find that:

(1) If $\theta$ is equal to or higher than $\alpha_{I}$ and $\alpha_{E}$, thenas would be the case with a fully honest regulator-supports $\omega$ and $\lambda$ are zero (they cannot be negative), and the access price $a^{*}$ equals $R^{\prime} \mathrm{s}$ belief about $C$ (i.e. $C^{P}$ ).

(2) If $\theta$ is lower than $\alpha_{I}$ and $\alpha_{E}$, an interior solution develops; in the symmetric case (which we use as the benchmark to derive other results), both firms offer positive transfers, and the regulator receives a positive rent, but policy is unbiased as marginal transfers are equal to each other.

(3) If both firms $I$ and $E$ could coordinate their transfers and offer no support $(\omega=0$ and $\lambda=0)$, then the policy $a^{*}$ remains the same, but $R$ 's rents disappear $\left(U^{R}=0\right)$.

(4) When $\alpha_{I}$ increases, both firms increase their marginal supports, and policy $a^{*}$ is biased towards $I$ 's preferred one; yet, only $R$ benefits from this situation (both $I$ and $E$ end up being worse off).

(5) When $\theta$ increases, transfers are reduced, policy remains unbiased, $I$ and $E$ 's utilities go up and $R$ 's utility goes down.

(6) When $C^{P}$ goes up, $I$ 's marginal support $\omega$ decreases and $E$ 's marginal support $\lambda$ increases, biasing policy towards $E$ 's preference relative to the new $C^{P} ; I$ is better off, but $E$ and $R$ are worse off.

We can thus formulate the following propositions:

\section{Proposition 1a:}

When the regulated incumbent and the new entrant are domestic firms, the outcome of the regulatory game is mainly driven by their relative nonmarket influence. The stronger the incumbent's capacity to provide support to the regulator, the stronger the departure from the first-best regulatory policy. However, the more significant the policy is in affecting the performance of the sector, the smaller the magnitude of the departure from the first-best policy created by the incumbent's nonmarket influence.

\section{Proposition 1b:}

In case the regulated incumbent and the new entrant are of comparable nonmarket influence, the adopted

\section{Table 1. Policy and Rents Without Multinational Firms}

\begin{tabular}{|c|c|c|c|c|c|c|}
\hline & \multicolumn{6}{|c|}{ Incomplete information equilibrium without multinational firms } \\
\hline & 1 & 2 & 3 & 4 & 5 & 6 \\
\hline & Fully honest regulator & Benchmark & Coordination & $\alpha_{I}$ goes up & $\theta$ goes up & $C^{P}$ goes up \\
\hline \multicolumn{7}{|c|}{ Values of parameters } \\
\hline$\alpha_{I}$ & 2 & 2 & 2 & 3 & 2 & 2 \\
\hline$\alpha_{E}$ & 2 & 2 & 2 & 2 & 2 & 2 \\
\hline$\theta$ & 2 & 1 & 1 & 1 & 1.5 & 1 \\
\hline$C^{P}$ & 3 & 3 & 3 & 3 & 3 & 4 \\
\hline$C^{I}$ & 5 & 5 & 5 & 5 & 5 & 5 \\
\hline$C^{E}$ & 1 & 1 & 1 & 1 & 1 & 1 \\
\hline \multicolumn{7}{|c|}{ Equilibrium values of supports, policy and utilities } \\
\hline$\omega^{*}$ & 0.00 & 4.00 & 0.00 & 6.00 & 2.00 & 3.14 \\
\hline$\lambda *$ & 0.00 & 4.00 & 0.00 & 5.50 & 2.00 & 4.86 \\
\hline$\omega^{*}+\lambda^{*}$ & 0.00 & 8.00 & 0.00 & 11.50 & 4.00 & 8.00 \\
\hline$\omega^{*}-\lambda^{*}$ & 0.00 & 0.00 & 0.00 & 0.50 & 0.00 & -1.71 \\
\hline$a^{*}$ & 3.00 & 3.00 & 3.00 & 3.25 & 3.00 & 3.14 \\
\hline$U^{I}$ & -8.00 & -16.00 & -8.00 & -22.69 & -12.00 & -13.63 \\
\hline$U^{E}$ & -8.00 & -16.00 & -8.00 & -19.75 & -12.00 & -18.20 \\
\hline$U^{R}$ & 0.00 & 8.00 & 0.00 & 11.44 & 4.00 & 7.27 \\
\hline
\end{tabular}


regulation coincides with the first-best policy, and fir ms spend resources to balance each other's influence, leaving rents to the regulator.

These propositions are relatively intuitive and will be used as a baseline to assess the impact of regulated firm internationalization. Presumably, (incumbent) regulated firms will have less incentive to invest in geographical diversification if they can offer significant support to (i.e. exert high pressure on) the regulator and therefore dominate entrants in the political game. In most cases (particularly when the country's regulatory policy embraces competition and entry), however, the situation will be more symmetrical in the nonmarket arena, and the regulated firm will have to face entrants that will match their political investment, force them to push their own lobbying investment higher and will therefore lead to a poor outcome in terms of regulated access price and allowed profits. Hence, this approach provides an explanation for why regulated firms, in many cases, cannot effectively rely on nonmarket strategies to overcome the problem they face regarding the regulator (as highlighted in limitation 2 in Section 1). This is why (ceteris paribus) geographical diversification becomes one of the best options for some regulated firms.

\subsection{Internationally Diversified Regulated Firms}

Assume first that only one of the two regulated firms (say the incumbent, $I$ ) is a multinational with operations in a country where the cost of access is known to be positively correlated with the cost to be determined by the home regulator. Thus, by providing this additional information in an enhanced report, which we have assumed is firmly believed by higher government political officials $(G)$, the regulator is faced with a possible penalty imposed by political superiors if he or she disregards (or fails to convincingly reject) the information supplied by multinationals. To eliminate the expected penalty, the regulator could simply give full attention to $M$ 's report. If he or she was anticipated to behave in this way, both firms would not offer any supports, bringing to zero the regulator's rents. In general, $R$ could depart from $M$ 's report by carefully providing arguments that justify differences between the costs of access in the two involved countries. Thus, he or she will balance out the higher expected cost suffered by deviating from the policy fully on the basis of $M$ 's report with the benefits derived from the supports that he or she is offered, still leading to an interior solution now-ceteris paribus-biased vis-àvis the expected first-best policy. Indeed, both firms anticipate the higher cost suffered by $R$ if he or she deviates from the policy justifiable under $M$ 's report and will thus compute their transfers (supports) appropriately ex ante.

Notice that the expected penalty is presumably higher and increases more rapidly when the two countries involved are 'institutionally closer' to each other (the costs of the two incumbents are more correlated, and the expectation that $R$ should rely on the other country's revealed information is higher), providing, in this case, higher benefits for being $M$. Indeed, part of the higher credibility attached to $M$ 's report is natural because a biased report could be exposed by a proper comparison with its report presented in the foreign country, eventually causing embarrassment or damage to the public image of the multinational firm. (Notice that such credibility, thus, should be higher when $M$ is an incumbent in one country and an entrant in another because the inconsistency of reports would otherwise be maximum, but the idea is more general than this as there is always some sacrifice in the amount of possible misrepresentation across countries if the involved firm is a multinational acting in both countries.)

As before, firms offer supports $s_{j}(a)$ and provide biased information to the regulator. Given our previous simplifying model assumptions, the transfers offered by the firms adjust to the new parameters of $R$ 's utility function, that is, with higher $\theta(\hat{\theta}>\theta$, as $R$ 's intrinsic disutility regarding poor performance is composed of the higher cost needed to justify his or her decisions when these move away from the expected policy by $G$ ), and increased prior belief $C^{P}$ (now replaced by $C^{P M}>C^{P}$ ). That is, relative to the absence of a multinational firm, the equilibrium corresponds to a situation where both $C^{P}$ and $\theta$ simultaneously increase. From the previous results in Table 1, and assuming that the multinational is the incumbent (see columns 5 and 6), we can see the following:

(i) When $\theta$ increases, marginal transfers $\lambda^{*}$ and $\omega^{*}$ are reduced, policy $a^{*}$ remains unbiased, $I$ and $E$ 's utilities go up, and $R$ 's utility goes down.

(ii) When $C^{P}$ goes up, $I$ 's support $\omega^{*}$ decreases and $E$ 's support $\lambda^{*}$ increases, thereby biasing policy towards $E$ 's preference relative to the new $C^{P}$; yet, compared with the benchmark case where $C^{P}=\frac{\left(C^{I}+C^{E}\right)}{2}, I$ is better off, but $E$ and $R$ are both worse off.

So, combining the two effects, Table 2 contains some numerical illustrations showing that when $I$ is a multinational-meaning that both $C^{P}$ and $\theta$ increase-then 


\section{Table 2. Policy and Rents with a Multinational Firm}

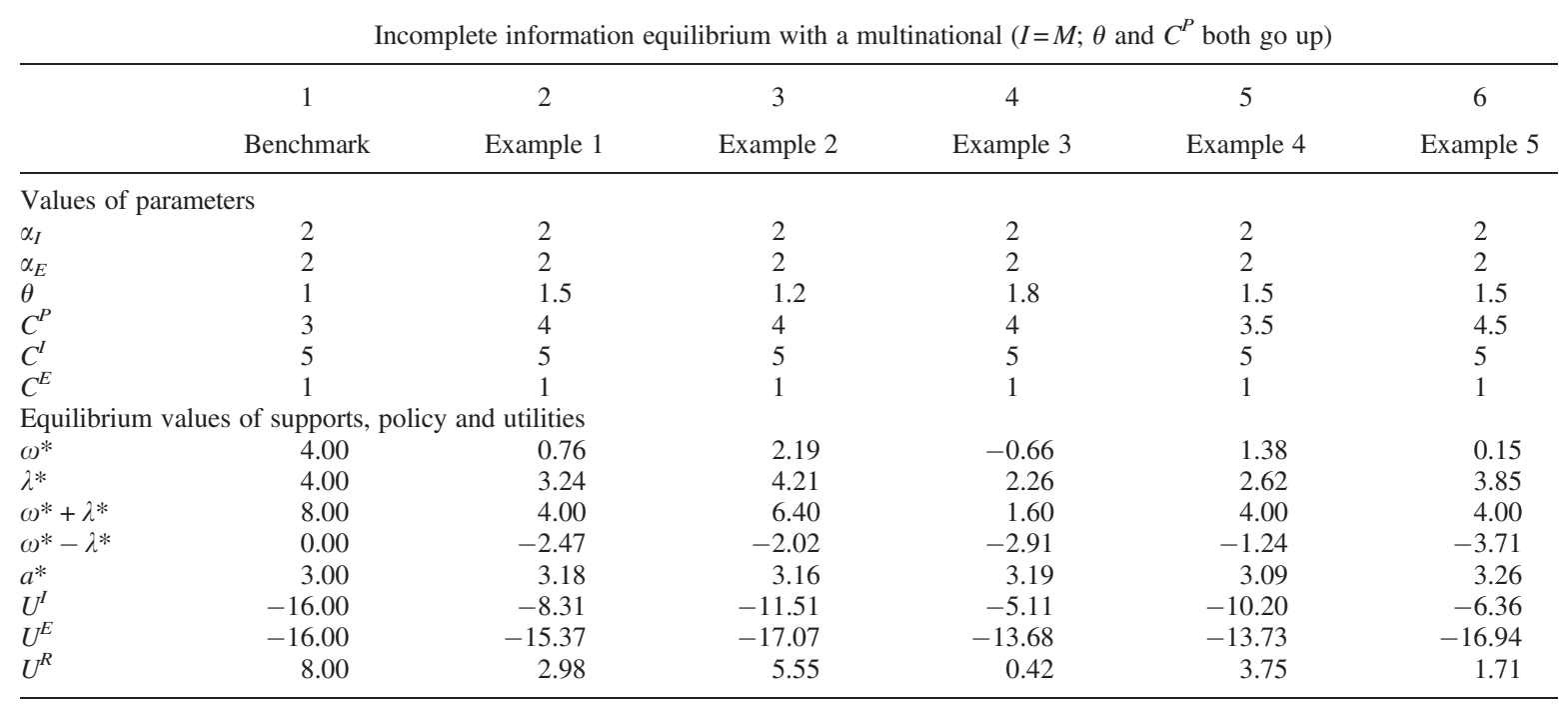

(a) $\omega^{*}$ goes down, and even though $\lambda^{*}$ could go up, still $\omega^{*}+\lambda^{*}$ (i.e. the aggregate level of marginal transfers received by $R$ in equilibrium) always goes down.

(b) $a^{*}$ goes up (although not as much as $C^{P}$ ).

(c) $U^{I}$ always goes up and $U^{R}$ always goes down, but $U^{E}$ can go up or down. ( $U^{E}$ is hurt by the intention to implement $C^{M}>E(C)$, but it is benefited by the fact that both firms reduce their marginal transfers once the regulator is less responsive to them.)

These results can be summarized in the following propositions:

\section{Proposition 2a:}

The smaller the regulated incumbent's nonmarket advantage over the new entrant, the higher the importance of information transmission (versus providing support) within its nonmarket strategy, and therefore the stronger the incentive for the incumbent to internationalize in order to increase its credibility/influence over the regulator.

\section{Proposition 2b:}

As internationalizing leads to a reduced scope of discretion for the regulator, both the regulated incumbent and the new entrant adapt their nonmarket strategies: marginal supports offered by each firm generally go down, but even if they do not, their sum will do so in equilibrium.

Notice that if the benchmark (without $M$ ) situation was instead one of asymmetric nonmarket power, the participation of a multinational could reduce or increase the implemented policy bias vis-à-vis the expected first-best policy, depending on who had relatively higher political strength prior to the higher credibility gained by the diversification. Yet, although this possibility would make the ex-post effect on the higher political officials (and final users) undefined, the reduced range of the possible bias benefits $G$ ex ante.

We can assume that the expected penalties imposed on regulators if they disregard (choose to discard without justification) reports by $M$ are positively related to the similarities between the two countries with respect to their regulatory environments: if there are closer cultural, geographical and/or institutional links between those countries, the importance given by $G$ to such international information becomes very high, whereas such importance (and thus the expected cost faced by $R$ for deviating from such a report) is relatively minor when the two countries are 'distant from each other' (in those same dimensions). Thus, it is logical to conclude that the benefits from internationalization (additional to other benefits and costs are not examined here) are higher when the two countries where the multinational acts are 'close to each other' - that is, sufficiently similar and connected regarding their regulatory systems. In other words, the credibility gained by being in two countries that are highly communicated and transparent (to each other) is higher than if the multinational acts in markets whose information flows are poor or where the idiosyncratic information in one country is not relevant to strengthen the credibility of the report about the idiosyncratic parameters in the other country. 
Finally, notice that the enhanced credibility from $M$ 's report is not related to the size of the investment abroad. Therefore, although returns for investments abroad (which are decided upon for traditional reasons) presumably depend on the amount invested, the diversifications in close countries directed to gain credibility might be of limited amounts, just enough to become a relevant player capable of collecting the information to be supplied to the home regulator (and, indirectly, to higher political officials).

Our data on the internationalization of telecom operators do not allow us to check this point in general, but we find initial support by comparing the cases of BT and FT. Recall that, according to Figure 2, BT is characterized as a company whose investments abroad might be particularly motivated by the strategic consideration we develop in the paper (i.e. it is weak regarding nonmarket strategies in the UK and thus seeks to improve its home position by investing in neighbouring countries), whereas FT is in the opposite situation (its home strength seems to be quite high, and it tends to invest more in far countries). Now, considering the evidence in Table 3, this characterization gains additional support: considering only those investments in close countries, BT's moves are much smaller (as shown by its stake in its close countries' ventures and the size of such firms) than those of FT.

\section{Proposition 3:}

Leaving other business features aside, (i) the (institutionally) closer the countries in which the regulated incumbent has invested and (ii) the more correlated the idiosyncratic costs parameters among these countries, the more positive the impact of internationalization on the effectiveness of the firm's nonmarket strategy (i.e. information transmission to the regulator).

Notice that, as a corollary of this proposition, firms that decide on the internationalization path for entering markets abroad, instead of limiting their activities to their home countries where they are incumbents, find a positive externality at home as the new markets they enter can serve as a benchmark and point of comparison. As this positive externality is higher in more

Table 3. International Investments: France Telecom Versus British Telecom

\begin{tabular}{lcc} 
& $\begin{array}{c}\text { Average stake } \\
\text { in ventures in } \\
\text { close countries }(\%)\end{array}$ & $\begin{array}{c}\text { Average number } \\
\text { of clients in close } \\
\text { countries }\end{array}$ \\
\hline $\begin{array}{c}\text { France Telecom } \\
\text { British Telecom }\end{array}$ & 78 & 6.25 million \\
\hline
\end{tabular}

Copyright @ 2012 John Wiley \& Sons, Ltd. mature and correlated markets, this would explain business strategies whereby long-time dominant players in the home markets of developed countries choose to enter neighbouring and institutionally similar markets despite obtaining a lower rate of return on the accounted investments abroad (as compared with that obtained, for instance, in less developed and more distant countries, with higher growth potential, where their strategies will not so seriously enhance their credibility at home). In other words, the differential profitability of expansions overseas might be missing some of the positive externalities obtained at home from various destinies abroad: mediocre or unprofitable accounting figures regarding investments in 'close countries', which implicitly assume that benefits at home in the absence of that particular diversification would have been the same as those obtained after the international expansion, might in fact be misleading. Our paper then reinforces previous research suggesting that the performance effect of diversification cannot be understood without reference to its original motives. ${ }^{20}$

Finally, we can think of $I$ and $E$ as two multinational firms, both reporting verifiable information that is still biased but less so than when they do not need to concern themselves with the consistency of reports sent across countries. In this case, $G$ could announce an auditing of the decision adopted by $R$ regarding how $R$ treated these two reports, weighting them according to the relevance attached to the country for which each $M$ submits cost information. This situation can be summarized-vis-à-vis the case where no multinational is involved-as one where the parameter $\theta$ increases and the support of the cost function shrinks in the two end points (i.e. $C^{\text {min }}$ increases and $C^{\max }$ decreases). While the increased credibility of a multinational depends on the significance given to its report vis-à-vis the other multinational's report, the two firms can now 'commit' to a lower support offered to the regulator because the regulator becomes less prone to exchange biases in policies for supports that could lead him or her to a high penalty if $G$ finds him or her to have been captured by one of the two interests offering transfers/supports.

Notice, further, that as the reports sent in by the two firms are closer to each other, and they still contain the true state of nature $C$ as an intermediate value, higher government officials can be sure that the expected bias in policy is now lower than that without multinational firms. Indeed, $G$ 's ability to monitor $R$ 's behaviour is significantly improved by inducing the regulator to justify departures from policy on the basis of reports that are less extreme and that reduce his or her discretion. 
This leads, then, to our final proposition.

\section{Proposition 4:}

When two competing multinationals are active in one country, the discretion enjoyed by the regulator is diminished, reducing the variability/indeterminacy to which higher political officials and final users are exposed. The highest benefit goes to the multinational firm submitting information about countries that are considered to be more relevant, as benchmarks, by government officials.

\section{PERSPECTIVES}

This paper has attempted a step towards a better understanding of why and how regulated firms diversify and, more precisely, why international diversification creates a specific advantage, which has not been identified by the previous literature, compared with product diversification. The model developed here suggests that international diversification might make sense for some regulated firms even if they do not expect direct benefits from the international venture itself, and it also allows us to identify the cases in which this circumstance occurs. We do not argue that building credibility is the only motive driving international acquisitions of regulated firms, nor that informational lobbying is restricted to such strategy. Rather, we argue that this logic might play an important role among other factors and in certain situations.

\subsection{Contributions}

This paper makes contributions to three areas of literature. First, it contributes to the International Business literature, especially the literature on the benefits of multinationalization (Hennart, 2007), by looking at specific benefits of internationalization that have not been explored before. In line with Goerzen and Beamish (2003), we find that international strategies will have different performance impacts depending on the 'geographical scope' (i.e. the number of countries in which the firm has invested) and the 'country environment diversity' (i.e. the economic, political and cultural differences across countries). Although these authors suggest that country environment diversity will have a negative impact on an international firm's performance, whereas more homogeneity should lead to better results, we show that, for regulated firms, country 'environment homogeneity' (i.e. the absence of diversity), at least at the institutional level, could be a rational strategy for companies facing a strong nonmarket competition domestically.

Furthermore, our explanation for why 'environment homogeneity' (called institutional closeness here) can be attractive is not a capability argument regarding production. Irrespective of whether a firm has a competitive advantage or some non-tradable, very specific or hardto-imitate assets, that is, the major factors explaining the success of international strategies (Buckley and Casson, 1976; Dunning, 1979), its internationalization moves might still be successful. In the case of regulated firms, we show that this comes from the credibility enhancement that the firm obtains in its home market vis-à-vis the regulator. Our argument complements—but is also different from-the 'liability of foreignness' argument (Zaheer, 1995) underlining that firms invest in neighbouring countries because their knowledge and capabilities are sufficiently close so as to make the investment attractive (Delios and Henisz, 2003; Markusen, 2004). The common point is that, for both reasons, firms will often end up investing in countries that are close to them institutionally. However, our explanation does not build on any assumptions regarding resources and capabilities associated with the target country. On the other hand, we argue that regulated firms with limited control of the regulatory process at home have an additional reason to invest in neighbouring countries (and thus would tend to do so more often, perhaps in small amounts) to enhance their own credibility vis-à-vis the regulator in their home country. Our argument also provides a rationale for the puzzle underlined by Holburn (2001), that is, that regulated firms tend to invest in countries whose regulated sectors have market structures (from monopsony to competition) similar to the market structure of the firm's home country. In our framework, comparisons related to prices and costs are indeed much easier for the regulator to make when market structures are comparable.

Second, this paper contributes to the literature on nonmarket strategies and, more precisely, on how firms can integrate market and nonmarket strategies (Baron, 1995, 2001; Hillman and Keim, 1995). The general idea in the existing literature is that nonmarket strategies complement market strategies by making market entry possible, by overcoming regulatory hurdles in the case of a new technology launch, by increasing competitors' costs, and so on (Yoffie and Bergenstein, 1985). In the situation presented here, however, we go one step further in this idea relative to the integration of market and nonmarket activities. We discuss a situation in which the regulated firm attempts to support its domestic market position through political support but, 
because this support is not very effective, the firm develops a market strategy (internationalization) that will strengthen its nonmarket activities (by gaining credibility or incidence at home). In the end, a market strategy is developed to support a nonmarket strategy, a situation which has not yet been highlighted in the literature.

Regarding nonmarket strategies, our paper also contributes to the literature on the combination of specific nonmarket activities (de Figueiredo and de Figueiredo, 2002; Schuler et al., 2002) by showing how traditional political support (e.g. votes, campaign contributions) and informational lobbying can be combined.

Third, this paper can also provide insights regarding public policy. The economic theory of regulation generally considers a theoretical setup with one regulator and one (or several) regulated firms in one country market. The result is that the information asymmetry makes it difficult for the regulator to efficiently regulate this type of situation. What happens then when regulated firms are multinationals and operate in several markets? Our model suggests that, in this case, the regulator has less discretion and thus his or her political superiors (who represent final users) might find a way to better control the regulatory authority they have previously delegated, preventing the regulator from being too biased against and/or dependent on the relative nonmarket efforts regarding lobbying and supports offered to them.

\subsection{Limitations and Extensions}

There are some additional empirical implications and testable hypotheses flowing from our model (particularly from Proposition 3). These extensions have to do with the types of diversification in which regulated firms might engage, and with the countries that these firms might target in the context of their international expansion.

4.2.1. Types of diversification. Considering the variations in the importance given to foreign countries as benchmark or informational sources in the home country (previously summarized by the expected penalty faced by each regulator for disregarding $M$ 's report), various types of diversification can be expected. If this importance is low, then firms will be less inclined to use international expansion as a way to overcome the credibility issue they face towards their domestic regulator. On the other hand, this becomes an option as soon as the importance given to such benchmark reports becomes high. From this analysis, the following conceptual framework (Table 4) emerges to account for the diversification strategies of regulated firms.

Even if the key contribution of our paper can be seen as being in cell (4) in Table 4, the other cells also stem from our formal framework and can be used to guide future empirical research. Clear predictions follow: ceteris paribus, international expansion will be the highest for firms in cell (4), and diversification in regulated products will happen mainly for firms in cell (1) and diversification in unrelated products for firms in cell (3). From this perspective, our approach should encourage future research regarding how international and product diversification interact (Sambharya, 1995; Wiersema and Bowen, 2008), particularly in the case of regulated firms for whom they seem to interact also through nonmarket activities (Bonardi, 2004; Kashlak and Joshi, 1994).

4.2.2. Variations regarding target countries. Linked to the importance given to foreign countries as benchmarks or informational sources in the home country, interesting predictions arise when we consider the types of countries that regulated firms are likely to target. In our framework, a foreign country can be a good target for a regulated firm for two different reasons: (i) because there is market growth potential or possibilities to obtain a monopoly position (traditional reasons) and (ii) because it helps to solve the credibility issue (a new reason provided in this paper).

For regulated firms in developed countries, investing in geographically/institutionally close countries is rarely attractive for traditional reasons, as competition is tough and growth perspectives are low there. However, a close developed country can be attractive

\section{Table 4. Regulated Firms' Nonmarket Strategies and Diversification}

\begin{tabular}{lll} 
& Dominant in domestic nonmarket arena & Non-dominant in domestic nonmarket arena \\
\hline $\begin{array}{l}\text { Low importance given to information } \\
\text { from foreign country }\end{array}$ & $\begin{array}{l}\text { (1) Least degree of international expansion. } \\
\text { Diversification in regulated products }\end{array}$ & $\begin{array}{l}\text { (2) Poor options. International expansion } \\
\text { will not help solve domestic problems. Rather, } \\
\text { the firm diversifies in unregulated activities }\end{array}$ \\
$\begin{array}{ll}\text { High importance given to information } \\
\text { from foreign country }\end{array}$ & $\begin{array}{l}\text { (3) Indeterminate-Mix of geographical } \\
\text { diversification and diversification in }\end{array}$ & (4) Mainly international expansion as a way to \\
regulated products & solve the credibility problem
\end{tabular}


because it helps solve the credibility issue. On the other hand, diversification in far countries (especially developing countries) is more attractive for traditional reasons (stronger market growth and, therefore, higher expected pay-offs). Yet, operating in developing countries will probably not help much to enhance the firm's credibility towards the regulator in its domestic country.

Thus, an important implication follows: the commercial benefits of investing in developing countries need to be much higher-even correcting by higher cost of capital or risk-than for investments expanding operations to neighbouring or developed countries. The theory behind this proposition is that investing in developed countries buys credibility at home, and therefore its true pay-off should include better results at home than the (correct but unobservable) counter-factual, where incumbents would suffer higher entry or more demanding access regulation. More work is certainly warranted to further explore these dimensions and empirically test the ideas developed in this paper.

\section{NOTES}

1. Here, we leave aside 'non-strategic' types of explanations for regulated firm diversification, such as the free cash-flow hypothesis (Jensen, 1986). According to this hypothesis, managers of firms with weak internal and external governance environments, and limited opportunities for profitable growth in their core businesses will divert resources into diversifying strategies, even where the latter involve investments with negative net present values. This type of argument might explain some of the variance in regulated firms' diversification performances, but we concentrate here on aspects related to firm external environment rather than internal and governance aspects.

2. There is a literature on how 'soft' information can be conveyed to policy-makers (see Grossman and Helpman (2001) for a survey). However, it is often difficult for firms to convey this information credibly to a regulator because the firm's pay-offs mainly depend on the policy adopted, which is based on the information disclosed (Lyon and Maxwell, 2004). Dahm and Porteiro (2008) developed a model of informational lobbying addressing its credibility and argue that it depends on the commitment to disclose all (beneficial and damaging) hard information to the regulator.

3. For broadly measuring the degree of regulatory restriction in firm home market, we consider here market shares in the wireless phone market. The underlying assumption here is that former monopolies that have lost largest market shares are those that have faced the most hostile regulatory environment, favouring new entrants to the detriment of incumbents. Up to a recent period (and because of technological breakthroughs in wireless telecom), it was indeed very difficult for new entrants to expand without significant intervention from regulatory authorities (Bonardi et al., 2009).

4. Clearly, counting the number of countries is a crude measure of international expansion. Yet, although gathering good data on the amount invested by each operator would allow us to contrast our results, these data were not easily available for most operators. More importantly, the prediction of our model has to do in fact with presence more than with the amount invested in close countries abroad.

5. See de Figueiredo et al. (1999) for an analysis of competition among interest groups, in which groups send biased reports to the regulator, thereby limiting the discretion and informational advantages of regulators vis-à-vis political officials. See also Krishna and Morgan (2001), where sequential biased reports by interested experts with opposed interests can reduce (but not eliminate, unless the rebuttal opportunities are unbounded) the degree of uncertainty for the decision maker regarding the true value of a relevant parameter observed by them.

6. Our definition of institutional proximity is close to what Mukand and Rodrik (2005) called 'closeness in the underlying state' when they look at policy convergence.

7. We consider only those operators present in more than two foreign countries.

8. One potential criticism to Figure 2 could be that part of the internationalization of European operators was driven by countries being former colonies. Mali is for instance a 'far' country for FT in Figure 2, but one cannot ignore the fact that Mali was a French colony. So there is cultural or historical proximity there. As we were concerned by this, we recomputed the data by adding former colonies to the number of close countries for the relevant operators. We do not report the new graph here, but when we do this, the overall picture remains unaffected. As could be expected, BT and FT move up vertically, but only slightly. Both had quite a large number of colonies and have invested in them. FT moves from 0.14 to 0.27 in terms of our index of 'alike internationalization'. BT moves from 0.3 to 0.42 . Qualitatively, however, this does not significantly change the outlook of the figure. The only operator that changes quadrants is Telefonica from Spain, which becomes an outlier on the upper right part of the figure. By adding most of the South American countries to the close countries, Telefonica goes from an index of 0.18 to 0.77 . As we will see later in the paper, though, this does not affect the key argument we are trying to make. Our argument is about whether the home regulator will use data from close countries to make regulatory decisions. Despite that Nicaragua was a Spanish colony, it is somewhat less likely that the Spanish regulator, when considering regulatory decisions regarding Telefonica in Spain, will consider comparative data from Nicaragua.

9. The disputes between incumbents and entrants are of course extended beyond the access price for the use of the existing infrastructure, but we use this dimension as an illustration of the general conflict between firms with opposed interests at home (see Madsen and Walker, 2007, who look at competitive rivalry in a deregulated industry). 
10. We focus here on the regulated incumbent's strategy and do not consider cases in which the new entrant could also be (or become) an international player and provide a competing benchmark to the regulator. These situations, in any case, would shape varying exogenous conditions faced by the incumbent firm and thus would not modify the model itself.

11. In particular, fixed network costs or economies of scale are disregarded. Access pricing in the context of Ramsey pricing (optimal deviations from marginal cost due to budget constraints and linear pricing) is primarily discussed in Armstrong et al. (1996).

12. The common agency model here is not one of formal delegation, but instead one where principals exert 'economic influence' on a common agent, who cannot refuse to act as such. The incentives or support can be offered through various means discussed in the literature, such as making campaign contributions, voicing opposition or accepting their general policy initiatives, future employment or economic bribes.

13. Thus, contrary to the most usual agency settings where the agent is better informed than the principal(s), in our model, the two principals (firms) perfectly observe the action taken by the agent (his or her policy decision $a)$, and they are both better informed than the agent regarding the state of nature $(\delta)$.

14. As foreign regulation might be biased and each vector $\delta$ partly reflects intrinsic characteristics of each country, pure imitation (of foreign regulation) is generally undesirable. More generally, multinational firms cannot be penalized for reporting different $\delta$ in different countries.

15. This happens once the final price of services $P^{f}$ is not fully adjusted to reflect different access prices. So, we implicitly assume that $P^{f}$ and $a$ are partly (but not fully) correlated: (i) if $P^{f}$ and $a$ change by the same amount, the entrant's margin ' $m$ ' $\left(=P^{f}-a\right)$ would not vary with $a$, and this would contradict our assumption about the entrant's utility function (preferring a lower access price); (ii) if $P^{f}$ remained constant when $a$ changed, no effect on final performance would emerge from various levels of access price (i.e., its effects would be purely on the division of rents between firms, which is not important for final consumers). See Armstrong et al. (1996).

16. The strength surely depends on several other things, including the political importance of the firm in its country, its role as a major employer, the support of trade unions, and so on, but we represent only its own economic stake as a determinant of the resources dedicated and useful to shape public policy.

17. If $R$ did adopt $M$ 's report as his or her new expected cost of access, the simplification made here would be fully correct: $C^{P}$ and $C^{M}$ would now coincide, and thus $U_{R}=$ $-\theta \times\left(a-C^{P}\right)^{2}+S_{I}(a)+S_{E}(a)-F \times\left(a-C^{M}\right)^{2}$ would reduce to $U_{R}=-(\theta+F) \times\left(a-C^{M}\right)^{2}+S_{I}(a)+S_{E}(a)$, so that, in the last equation, $\hat{\theta}=\theta+F$ and $C^{P M}=C^{M}$.

18. The interior solution requires that the preferences of the firms regarding the policy to be implemented $\left(\alpha_{I}\right.$ and $\left.\alpha_{E}\right)$ are larger than the marginal impact of policy on performance (or, in other words, the intrinsic policy preference of the regulator, $\theta$ ): if this is not the case, then there is no room for profitable exchanges of supports and policies.
19. When $C^{P}=\frac{\left(C^{I}+C^{E}\right)}{2}$, then $\frac{\partial a *}{\partial \theta}=3 \times\left[\left(C^{P}-C^{E}\right) \times\right.$ $\left(\alpha_{E}-\alpha_{I}\right] /\left(\alpha_{E}+\alpha_{I}+3 \theta\right)^{2}$, and thus the signs of $\frac{\partial a *}{\partial \theta}$ and $\alpha_{E}-\alpha_{I}$ coincide, meaning that, when $\theta$ increases, $a^{*}$ tends to move to the centre of $C$ 's distribution from the biased choice induced by the stronger interest group (i.e. if $\alpha_{E}>\alpha_{I}$, then $a^{*}$ would initially be downward biased (towards the entrant's preference) but would then increase (reduce its bias) as the impact of policy on efficiency- $\theta$-increases).

20. Hill and Hansen (1991) showed, for instance, that the diversification of pharmaceutical firms has been primarily undertaken to reduce the risks of being dependent upon a technologically dynamic environment; this suggests, as we do here, that diversification investments might have motives that are not directly related to financial performance.

\section{REFERENCES}

Armstrong M, Doyle J, Vickers J. 1996. The access pricing problem: a synthesis. Journal of Industrial Organization 44: 2.

Baron DP. 1995. Integrated strategies: market and nonmarket components. California Management Review 37(2): 47-65.

Baron DP. 1997. Integrated strategy and international trade disputes: the Kodak-Fujifilm case. Journal of Economics and Management Strategy 6(2): 291-346.

Baron DP. 2001. Theories of strategic nonmarket participation: majority-rule and executive institutions. Journal of Economics and Management Strategy 10(1): 46-89.

Bernheim DB, Whinston MD. 1986. Menu auctions, resource allocation, and economic influence. Quarterly Journal of Economics 101(1): 1-32.

Bonardi JP. 2004. Political and international strategies of former telecom monopolies: the asymmetric behaviors of former monopolies. Strategic Management Journal 25 (2): 101-120.

Bonardi JP, Holburn G, Van den Bergh R. 2006. Nonmarket strategy performance: evidence from U.S. electric utilities. Academy of Management Journal 49: 1209-1228.

Bonardi JP, Urbiztondo S, Quélin B. 2009. The political economy of international regulatory convergence in public utilities. International Journal of Management and Network Economics 2(1): 232-256.

Buckley P, Casson M. 1976. The economic theory of foreign investment. Economica 28: 1-27.

Calzolari G. 2004. Incentive regulation of multinational enterprises. International Economic Review 45: 257-282.

Dahm M, Porteiro N. 2008. Informational lobbying under the shadow of political pressure. Social Choice and Welfare 30(4): 531-559.

Delios A, Henisz WJ. 2003. Political hazards, experience and sequential entry strategies: the international expansion of Japanese firms, 1980-1998. Strategic Management Journal 24(12): 1153-64.

Dunning JH. 1979. Explaining changing patterns of international production: in defence of the eclectic theory. Oxford Bulletin of Economics and Statistics 41: 269-295. 
de Figueiredo JM, de Figueiredo RJ. 2002. The allocation of resources by interest groups: lobbying, litigation, and administrative regulation. Business and Politics 4(2): 161-181.

de Figueiredo RJ, Edwards G. 2007. Does private money buy public policy? Campaign contributions and regulatory outcomes in telecommunications. Journal of Economics and Management Strateg 16(3): 547-576.

de Figueiredo JM, Tiller EH. 2001. The structure and conduct of lobbying: an empirical analysis of corporate lobbying at the federal communications commission. Journal of Economics and Management Strategy 10(1): 91-122.

de Figueiredo RJ, Spiller PT, Urbiztondo S. 1999. An informational rationale for the Administrative Procedures Act. Journal of Law, Economics and Organization 15: 1.

Garcia Canal E, Guillen M. 2008. Risk and the strategy of foreign location choice in regulated industries. Strategic Management Journal 29: 1097-1115.

Geiger SW, Hoffman JJ. 1998. The impact of the regulatory environment and corporate level diversification on the firm performance. Journal of Managerial Issues 10(4): 439-453.

Goerzen A, Beamish PW. 2003. Geographic scope and multinational enterprise performance. Strategic Management Journal 24(13): 1289-1306.

Grossman G, Helpman E. 1994. Protection for sale. American Economic Review 84(4): 833-850.

Grossman G, Helpman E. 2001. Special Interest Politics. The MIT Press: Cambridge, MA.

Hennart JF. 2007. The theoretical rationale for multinationalityperformance relationship. Management International Review 47(3): 423-452.

Hill CW, Hansen GS. 1991. A longitudinal study of the causes and consequences of changes in diversification in the U.S. pharmaceutical industry 1977-1986. Strategic Management Journal 12: 187-200.

Hillman A, Keim G. 1995. International variation in the business-government interface: institutional and organizational considerations. Academy of Management Review 20: 193-214.

Hillman A, Keim G, Schuler D. 2004. Corporate political strategy: a review and research agenda. Journal of Management 30: $837-857$.

Holburn G. 2001. Regulatory institutions and firm strategy: theory and evidence from the electric power industry.
Mimeo, PhD dissertation, University of California Berkeley, Haas School of Business.

Holburn G, Van den Bergh R. 2008. Making friends in hostile environments: political strategy in regulated industries. Academy of Management Review 33(2): 521-540.

Hyman LS. 2000. America's Electric Utilities: Past, Present, and Future. ( $7^{\text {th }}$ edn). Public Utilities Reports: Vienna, VA.

Jensen M. 1986. Agency costs of free cash flows, corporate finance and takeovers. American Economic Review 76: 323-329.

Kashlak R, Joshi M. 1994. Core business regulation and diversification patterns in the telecommunications industry. Strategic Management Journal 15: 603-611.

Krishna V, Morgan J. 2001. A model of expertise. Quarterly Journal of Economics 116(2): 747-775.

Laffont J-J, Tirole J. 1993. A Theory of Incentives and Regulation. The MIT Press: Cambridge, MA.

Lyon TP, Maxwell JW. 2004. Astroturf: interest group lobbying and corporate strategy. Journal of Economics and Management Strategy 13(4): 561-597.

Madsen T, Walker G. 2007. Incumbent and entrant rivalry in a deregulated industry. Organization Science 18(4): 667-687.

Markusen J. 2004. Multinational Firms and the Theory of International Trade. The MIT Press: Boston, MA.

Mukand S, Rodrik D. 2005. In search of the Holy Grail: policy convergence, experimentation and economic performance. American Economic Review 95(1): 374-383.

Russo MV. 1992. Power plays: regulation, diversification and backward integration in the electric utility industry. Strategic Management Journal 13: 13-27.

Sambharya R. 1995. The combined effect of international diversification and product diversification strategies on the performance of U.S. based multinational corporations. Management International Review 35: 197-218.

Schuler D, Rehbein K, Cramer R. 2002. Pursuing strategic advantage through political means: a multivariate approach. Academy of Management Journal 45: 659-672.

Wiersema M, Bowen H. 2008. Corporate diversification: the impact of foreign competition, industry globalization, and product diversification. Strategic Management Journal 29: 2.

Yoffie D, Bergenstein S. 1985. Creating political advantage: the rise of the corporate political entrepreneur. California Management Review 28(1): 124-139.

Zaheer S. 1995. Overcoming the liability of foreignness. Academy of Management Journal 38: 341-363. 